\section{Couple and Relationship Therapy (Journal)}

Volker Thomas

The University of Iowa, Iowa City, IA, USA

\section{Introduction}

The Journal of Couple \& Relationship Therapy promotes a better understanding of what contributes to healthy adult relationships and how therapy facilitates the process. Experts address key treatment issues for all types of adult relationships. Articles explore couple therapy from the perspectives of theory, research, and practice, as well as issues related to the supervision and personal growth of clinicians. Special thematic issues address a single topic for the entire issue, allowing a more significant focus on that particular topic. Recent thematic issues studied clinical concerns with interracial couples, and research and treatment models addressing trauma in couples.

\section{Contributions}

The Journal of Couple \& Relationship Therapy discusses important issues from a multiplicity of therapeutic styles including:

- Marital therapy

- Couple therapy

- Same-sex couple therapy

- Premarital therapy

- Re-marital therapy

- Divorce therapy

- Sex therapy

- Marriage therapy

- Couple therapy as adjunct to the treatment of major mental illness, substance abuse, and spouse and family abuse

\section{Peer Review Policy}

Each paper is first briefly reviewed by the editor for adherence to our standards of science and APA style. If the paper fits our content and purposes as a journal, it is sent out for review to a minimum of two reviewers, usually members of our editorial board, consisting of some of the country's most prestigious scholars and therapists. Upon completion of reviews, the editor makes a decision about publication. 